\title{
Delirium Café: interactive learning to enhance delirium care
}

\author{
Hanna-Maria Roitto ${ }^{1,2} \oplus \cdot$ Ulla Liisa Aalto ${ }^{1,2} \cdot$ Riikka Söderling $^{2} \cdot$ Marja-Liisa Laakkonen $^{1,2} \cdot$ Hanna Öhman $^{1,2}$
}

Received: 10 October 2019 / Accepted: 14 December 2019 / Published online: 10 January 2020

(c) The Author(s) 2020

\section{Key summary points}

Aim The aim of Delirium Café was to try a new learning method to increase awareness of delirium and improve delirium care in an acute hospital setting.

Findings Delirium Café seems to be both feasible and applicable as a new interactive-learning method in postgraduate medical teaching.

Message It is important to create opportunities of stimulating learning. Delirium Café is a good example of a model that is both creative and interactive.

\begin{abstract}
Purpose The aim of Delirium Café was to try a new learning method to increase awareness of delirium and improve delirium care in an acute hospital setting in Helsinki, Finland.

Method World Café-an active learning method, with four facilitators and four stations covering important aspects of delirium recognition and management, was used.

Results 22 junior doctors and 4 members of the senior staff participated in the event on 13th of March 2019, the World Delirium Awareness Day (WDAD). Nobody dropped out during the $1 \mathrm{~h}$ training. Feedback on the educational method was positive.

Conclusion Delirium Café seems to be both feasible and applicable as a new interactive-learning method in postgraduate medical teaching.
\end{abstract}

Keywords Delirium $\cdot$ World cafe $\cdot$ Education $\cdot$ Geriatrics

\section{Introduction}

Delirium recognition and management continues to be a challenge in different health care settings [1]. For this reason, the International Federation of Delirium Societies launched in 2017 World Delirium Awareness Day (WDAD). WDAD is an international effort to increase awareness of delirium among patients, carers, health care professionals, administrators, and policy makers [2]. WDAD takes place every year on the second Wednesday of March. Health care professionals are called to take action to help spread awareness and

Hanna-Maria Roitto

hanna-maria.roitto@hel.fi

1 Department of General Practice, University of Helsinki, Helsinki, Finland

2 Department of Social Services and Health Care, Helsinki Hospital, PO Box 6600, 00099 Helsinki, Finland understanding of delirium on WDAD and also during the rest of the year. One of the suggested actions in 2019 was to educate health care professionals about delirium.

It has been argued that adult education should include interactive and experiential learning [3]. This means that learners experience things for themselves and learn from these experiences. This model was proposed by Kolb in 1984 and it is known as the experiential learning cycle [4]. Learners modify their behavior after reflecting their own experiences and thinking. One way to organize experiential learning is simulation. Another often used method in adult education is the World Café method [5].

In the spirit of WDAD and to assess and improve delirium knowledge of junior doctors, we decided to organize an interactive-learning event called Delirium Café. The aim of Delirium Café was twofold, to try a new learning method, and to increase awareness of delirium and thus improve 
delirium care in an acute hospital setting in Helsinki Hospital in Finland.

\section{Methods}

We got together a working group from Helsinki Hospital to plan the event. The group consisted of five geriatricians who were mostly current or past European Academy of Medicine of Ageing (EAMA) students, thus having been disposed to a wide range of interactive-teaching methods. The members of the working group were Ulla Aalto, Home Care Services (EAMA 2019-2020), Hanna Öhman, Ortogeriatric ward (EAMA 2016-2017), Riikka Söderling, Acute geriatric ward, Hanna-Maria Roitto, Geriatric memory clinic (EAMA 2017-2018), and Marja-Liisa Laakkonen, Geriatric memory clinic (EAMA 2007-2008).

We organized the event on WDAD, on 13th of March, from 8 to 9.00 in Laakso Hospital lecture hall. The event was targeted to junior doctors, but senior consultants were also encouraged to attend. Following the theme of WDAD 2019, "Calling all delirium heroes", the event was called Delirium Superhero-course. We arranged four stations covering all the important aspects of delirium recognition and management. The participants were divided randomly into 4 groups on arrival, thus guaranteeing equal number of participants in each group.

The event began with a short introduction to the theme and tasks, before the participants were directed to their stations. The duration of each station was $12 \mathrm{~min}$. Changing of stations was announced by bell rings. After completing each station the participants got a small card stating the 3 most important take home messages of the station. After having completed all 4 stations, the participants were given the covers to their take home messages, thus creating a small booklet that held all the take home messages. The first page had a blank space for participant's name, indicating that the Delirium Superhero-course was completed on the 13th of March 2019. The last page had a blank space, where the participants were encouraged to write which special delirium friendly task they were going to perform later that day on their own ward. Coffee and cake were available for all the participants free of charge during the whole event. To add to the atmosphere, a Delirium Café playlist was created in Spotify. The $1 \mathrm{~h}$ long playlist, including songs themed in delirium, hospitals, doctors, and medication, was played during the event.

Each station had a facilitator who remained during the whole event, while the participants moved from one station to another. The facilitator led the discussion to make sure everyone participated. The four stations were: delirium recognition, risk factors of delirium, non-pharmacological treatment of delirium, and pharmacological treatment of delirium.

At the first station, the participants were given three real patient cases of hospitalized patients to read. Their task was to decide who of the patients had delirium and which test they would use to detect it. They were given eight different tests to choose from. The tests included two correct tests 4AT (rapid clinical test to detect delirium) [6] and CAM (confusion assessment method) [7], and six incorrect tests including mini mental state examination (MMSE) [8], Montreal Cognitive Assessment (MOCA) [9], the consortium to establish a registry for Alzheimer's disease (CERAD) [10], Geriatric Depression Scale (GDS) [11], Neuropsychiatric Inventory (NPI) [12], and Cohen-Mansfield Agitation Inventory (CMAI) [13]. The groups discussed the possible pit falls of delirium recognition and differential diagnostics based on the eight different tests and the three patient cases. The patient cases represented one case of delirium, one case of schizophrenia, and one case of dementia with severe neuropsychiatric symptoms.

At the second station, the participants were given approximately 50 cards describing possible predisposing risk factors and causes of delirium. The task of the group was to sort out the pile of words and to decide which factors could be associated with delirium. The participants were also encouraged to discuss strategies to prevent delirium.

The third station consisted of a simulation practice. The task of the group was to optimize the non-pharmacological treatment of a patient with delirium. The group started with a confused patient in a hospital bed, with the bed rails up, tucked tightly under the blankets, with an IV-line and a catheter. The walker, anti-slip socks, hearing aid, glasses and a glass of water were far away from the bed, not reachable by the patient, but in the field of visions of the participants. The patient was played by the chief of the geriatric memory clinic, Marja-Liisa Laakkonen. After the completion of the task, the participants received feedback given by both the facilitator and the "patient".

At the fourth station, the participants were given a patient case with a short medical history along with a medication list. They were instructed to go through the list and make suggestions to improve the patient's medications. The medication list included drugs with anticholinergic properties, psychotropics, opioids, as well as common cardiovascular medication. Furthermore, the participants had a discussion on which drugs would be the most suitable if a patient with severe delirium is considered to be at risk of harming himself or others. Several drugs were suggested on post-it notes. The participants had to choose between more appropriate drugs (e.g., low-dose antipsychotics) or some totally avoidable options (e.g., long-acting benzodiazepines).

The event lasted for $1 \mathrm{~h}$. The organizers then had a $15 \mathrm{~min}$ debriefing sharing experiences of the various stations and of 
the whole event. Notes of practical improvements for future sessions were also gathered.

\section{Results}

22 junior doctors and 4 members of the senior staff participated in the event. Nobody dropped out during the $1 \mathrm{~h}$ training.

\section{Discussion}

Delirium Café seems to be both feasible and applicable as a new interactive-learning method in postgraduate medical teaching. It is a good way to both assess the knowledge of junior doctors as well as offer them a new and fun way to improve their knowledge on delirium.

The most challenging, but also most memorable, station for the junior doctors was the non-pharmacological treatment of delirium. This was somewhat surprising, since these are the core elements of good geriatric care. One explanation for this could be that non-pharmacological methods are more often considered by nurses and therapist, while the physicians mostly concentrate on diagnostics and pharmacological treatment. In addition, the fact that our confused patient gave feedback on how she felt when doctors were talking over her and not to her, seemed to make an impression on the participants. Learning that the non-pharmacological treatment of delirium was most challenging for the junior doctors has helped to emphasize non-pharmacological treatment during senior ward rounds.

No official feedback was gathered, but during the informal feedback discussion, the participants shared their view on the event. Many told that they had experienced the new learning model as a practical and effective. Learning had been surprising, and in a good way. Many junior doctors also pointed out that they had had fun and they welcomed more of this kind of educational events in the future.

\section{Limitations}

We did not do pre/post evaluation on the knowledge levels of the participants; thus, we have no real data on whether the educational event improved the quality of delirium care or not. The time reserved for the event was limited. When organizing similar events in the future, we would suggest at least 15 min to be reserved for each station to guarantee enough time for discussion, and the whole event should take about $1.5 \mathrm{~h}$ with $15 \mathrm{~min}$ to open and close the event. Our participants were mainly junior doctors, but this kind of approach could be suitable for training also other health care professionals as well as multi-professional teams, which would be closer to the real ward settings. After the event was organized in March 2019, we have also organized the event for a group of the 5th year medical students, with similar results. The same model of learning could also easily be modified for other topics as well. One possible topic that we have discussed trying in the future is neuropsychiatric symptoms of dementia (NPS), where the stations could be divided into similar themes: NPS recognition, risk factors of NPS, non-pharmacological treatment of NPS, and pharmacological treatment of NPS.

In the spirit of WDAD, we shared our experiences in social media, especially in Twitter during the course of preparation and execution of our Delirium Café. Our new learning model attracted attention in different parts of the worlds, from Norway to New Zealand, finally leading us to share our experience in a more specific matter in the form of this article.

\section{Conclusions}

As new learning methods are always needed, Delirium Café could be a useful addition to the repertoire. The model once created is easily repeated as such, and by small changes, it can also be modified to various themes if needed. Learning through action and reflection promotes deeper thinking and can lead to a transformation, in this case thus enhancing delirium care.

Acknowledgements Open access funding provided by University of Helsinki including Helsinki University Central Hospital.

Funding None.

\section{Compliance with ethical standards}

Conflict of interest The authors declare that they have no conflicts of interest.

Ethical approval This article does not contain any studies with human participants or animals performed by any of the authors.

Informed consent For this type of study, formal consent is not required.

Open Access This article is licensed under a Creative Commons Attribution 4.0 International License, which permits use, sharing, adaptation, distribution and reproduction in any medium or format, as long as you give appropriate credit to the original author(s) and the source, provide a link to the Creative Commons licence, and indicate if changes were made. The images or other third party material in this article are included in the article's Creative Commons licence, unless indicated otherwise in a credit line to the material. If material is not included in the article's Creative Commons licence and your intended use is not permitted by statutory regulation or exceeds the permitted use, you will need to obtain permission directly from the copyright holder. To view a copy of this licence, visit http://creativecommons.org/licenses/by/4.0/. 


\section{References}

1. Velthuijsen EL, Zwakhalen SMG, Mulder WJ et al (2018) Detection and management of hyperactive and hypoactive delirium in older patients during hospitalization: a retrospective cohort study evaluating daily practice. Int J Geriatr Psychiatry. 33:1521-1529. https://doi.org/10.1002/gps.4690

2. iDelirium, The International Federation of Delirium Societies. http://idelirium.org/. Accessed 8 Oct 2019

3. Reed S, Shell R, Kassis K et al (2014) Applying adult learning practices in medical education. Curr Probl Pediatr Adolesc Health Care 44(6):170-181. https://doi.org/10.1016/j.cpped s.2014.01.008

4. Kolb DA (1984) Experiential learning: experience as the source of learning and development. In: Sternberg RJ, Zhang L (eds) Perspectives on thinking, learning, and cognitive styles. PrenticeHall, Englewood Cliffs, pp 223-227

5. Anderson L (2011) Use the World Café concept to create an interactive learning environment. Educ Prim Care 22(5):337-338. https://doi.org/10.1080/14739879.2011.11494028

6. Bellelli G, Morandi A, Davis DH et al (2014) Validation of the 4AT, a new instrument for rapid delirium screening: a study in 234 hospitalised older people. Age Ageing 43(4):496-502. https ://doi.org/10.1093/ageing/afu021

7. Inouye SK, van Dyck CH, Alessi CA et al (1990) Clarifying confusion: the confusion assessment method: a new method for detection of delirium. Ann Intern Med. 113:941-948. https://doi. org/10.7326/0003-4819-113-12-941

8. Folstein MF, Folstein SE, McHugh PR (1975) "Mini-mental state". A practical method for grading the cognitive state of patients for the clinician. J Psychiatr Res 12(3):189-198. https:// doi.org/10.1016/0022-3956(75)90026-6

9. Nasreddine ZS, Phillips NA, Bédirian V et al (2005) The montreal cognitive assessment, MoCA: a brief screening tool for mild cognitive impairment. J Am Geriatr Soc 53:695-699. https://doi.org /10.1111/j.1532-5415.2005.53221.x

10. Morris JC, Heyman A, Mohs RC et al (1989) The consortium to establish a registry for alzheimer's disease (CERAD). Part I. Clinical and neuropsychological assessment of alzheimer's disease. Neurology 39(9):1159-1165. https://doi.org/10.1212/ wnl.39.9.1159

11. Korner A, Lauritzen L, Abelskov K et al (2006) The geriatric depression scale and the cornell scale for depression in dementia. A validity study. Nord J Psychiatry. 60(5):360-364. https://doi. org/10.1080/08039480600937066

12. Medeiros K, Robert P, Gauthier S et al (2010) The neuropsychiatric inventory-clinician rating scale (NPI-C): reliability and validity of a revised assessment of neuropsychiatric symptoms in dementia. Int Psychogeriatr 22(6):984-994. https://doi.org/10.1017/ S1041610210000876

13. Cohen-Mansfield J, Marx MS, Rosenthal AS (1989) A description of agitation in a nursing home. J Gerontol 44(3):M77-M84. https ://doi.org/10.1093/geronj/44.3.m77

Publisher's Note Springer Nature remains neutral with regard to jurisdictional claims in published maps and institutional affiliations. 